\title{
Investigation of the role of the cytomegalovirus as a respiratory pathogen in HIV-infected patients
}

\author{
RAFAEL E DE LA HOZ MD MPH, SHIZU HAYASHI PhD, DARREL COOK MSc, \\ CHRISTOPHER SHERLOCK MD, JAMES C HOGG MD PhD \\ Respiratory Medicine Program, Pulmonary Research Laboratory, Diagnostic Virology and \\ Reference Laboratory, and Department of Pathology, University of British Columbia; and \\ British Columbia Center for Disease Control, Vancouver, British Columbia
}

RE DE la Hoz, S HaYaShi, D COOK, C SheRlock, JC HoGG. Investigation of the role of the cytomegalovirus as a respiratory pathogen in $\mathrm{HIV}$-infected patients. Can Respir J 1996;3(4):235-240.

OBJECTIVE: To investigate the occurrence of cytomegalovirus (CMV) pneumonitis in the setting of human immunodeficiency virus (HIV) infection and whether the presence of $\mathrm{CMV}$ as copathogen is associated with increased clinical severity or short term mortality in patients with Pneumocystis carinii pneumonia.

DESIGN: Retrospective cohort study.

SETTING: Tertiary care university hospital.

PATIENTS: One-hundred and fourteen HIV-infected homosexual men with pneumonia, followed for a minimum of four weeks.

MEASUREMENTS: Clinical indicators of severity of pneumonia, microbiology of bronchoalveolar fluid and relative risk of short term mortality.

RESULTS: Only two cases of CMV pneumonitis were found, one together with $P$ carinii. However, 45 of the 86 patients with $P$ carinii pneumonia were co-infected with CMV. No difference in clinical severity was detected between patients co-infected with $P$ carinii and CMV and those with $P$ carinii alone. The relative risk of short term mortality was 3.64 (95\% CI 0.82 to 16.18), in patients with co-infection compared with those with $P$ carinii alone. The risk reached statistical significance for patients with earlier stages of HIV infection.

CONCLUSIONS: CMV pneumonitis occurs rarely in HIV-infected patients, while CMV co-infection occurs in at least $50 \%$ of the cases of $P$ carinii pneumonia. Although no difference in clinical severity was detected, this study suggests that short term mortality from $P$ carinii pneumonia may be increased by CMV co-infection, particularly in patients with earlier stages of the disease.

Key Words: Copathogens, Cytomeglovirus pneumonitis, $\mathrm{Hu}$ man immunodeficiency virus infection, Pneumocystis carinii pneumonia

Investigation du rôle du cytomégalovirus comme pathogène respiratoire chez les patients infectés par le VIH

OBJECTIF : Investiguer l'apparition d'une pneumopathie à cytomégalovirus (CMV) dans le contexte d'une infection au virus de l'immunodéficience humaine (VIH) et essayer d'établir si l'existence du CMV comme copathogène est associée à une gravité clinique accrue ou à un taux de mortalité à court terme plus élevé chez les patients atteints d'une pneumonie à Pneumocystis carinii.

voir page suivante

Correspondence and reprints: Dr Rafael E de la Hoz, Bellevue Hospital Center, First Avenue at 27 Street, Room CD-349, New York, NY 10016, USA. Telephone 212-562-4572, fax 212-562-4574, e-mail hoz@is2.nyu.edu 
MODÈLE : Étude rétrospective de cohortes.

CONTEXTE : Hôpital universitaire de soins tertiaires.

PATIENTS : Cent quatorze homosexuels masculins infectés par le VIH, et présentant une pneumonie, suivis pendant un minimum de 4 semaines.

MESURES : Les indicateurs cliniques de la gravité de la pneumonie, l'examen microbiologique du liquide bronchoalvéolaire et le risque relatif de mortalité à court terme.

RÉSULTATS : Seulement deux cas de pneumopathie à CMV ont été mis en évidence, dont un associé à $P$ carinii. Cependant, 45 des 86 patients atteints d'une pneumonie à $P$ carinii étaient coïnfectés par le CMV. Aucune différence quant à la gravité clinique n'a été décelée entre les patients coïnfectés par $P$ carinii et le CMV et ceux infectés seulement par $P$ carinii.
Le risque relatif de mortalité à court terme était de 3,64 (95\% IC $0,82-16,18$ ) chez les patients coïnfectés comparativement à ceux infectés par $P$ carinii seulement. Ce risque atteignait une valeur significative pour les patients dans les phases les plus précoces de l'infection par le VIH.

CONCLUSIONS : La pneumopathie à CMV survient rarement chez les patients infectés par le VIH, alors qu'une coïnfection à CMV survient chez au moins $50 \%$ des patients atteints de pneumonie à $P$ carinii. Même si aucune différence de gravité clinique n'a été décelée, cette étude laisse à penser que la mortalité à court terme causée par la pneumonie à $P$ carinii pourrait être augmentée par une coïnfection au CMV, surtout chez les patients dans les phases précoces de l'infection par le VIH.
$\mathrm{R}$ espiratory infections constitute by far the major cause of morbidity and mortality in patients with the acquired immunodeficiency syndrome (AIDS), with Pneumocystis carinii being the most frequent etiological agent. Several viruses have also been reported as causes of pneumonitis in patients with AIDS and, of these, cytomegalovirus (CMV) is the most important (1-4).

CMV has been reported to be the second most frequent pulmonary pathogen in patients with AIDS (1-3,5,6) with autopsy series that report findings consistent with CMV pneumonitis in nearly $60 \%$ of all the cases studied (7-9). Moreover, it is a frequent copathogen with $P$ carinii, having been reported to increase mortality from $P$ carinii pneumonia (PCP) $(2,5)$.

However, the role of $\mathrm{CMV}$ as a respiratory pathogen in AIDS has been questioned (10-13). Although CMV is found in cultures of bronchoalveolar lavage fluid in $45 \%$ to $50 \%$ of the HIV-infected patients who undergo bronchoscopy (14), some investigators have reported that relatively few cases can be firmly characterized as CMV pneumonitis $(10,14,15)$. Moreover, the morbidity and mortality of these patients seem not to be affected by CMV infection $(10-12,16)$. The diagnosis of CMV pneumonitis (as opposed to infection) by current noninvasive diagnostic methods is very unreliable $(6,15,17$ 20).

In order to evaluate the characteristics of the respiratory CMV infections in patients with human immunodeficiency virus (HIV) infection and to assess whether a positive CMV culture of the fluid was associated with any increase in clinical severity and/or short term mortality from PCP, a retrospective review of 114 episodes of pneumonia in HIVinfected patients was conducted.

\section{PATIENTS AND METHODS}

The study was conducted at St Paul's Hospital, a tertiary care level university hospital in Vancouver, British Columbia, after approval from the institutional ethics committee had been obtained.

Patients: Patients met the following criteria: first, a diagnosis of HIV infection had either been established previously or was established within one week of bronchoscopy by HIV seropositivity (positive ELISA confirmed by Western blot technique). A Centers for Disease Control and Prevention (CDC) group class was assigned at the time of entry (21). Second, patients were evaluated by bronchoscopy because of clinical evidence of lower respiratory infection. Clinical evidence consisted of the presence of fever, cough or dyspnea; the presence of physical signs consistent with pneumonitis; and any of hypoxemia, abnormality in the chest radiograph or abnormality in gallium scan of the lungs according to previously published criteria (22).

The charts of $121 \mathrm{HIV}$-infected patients (who had experienced a total of 127 episodes of suspected pneumonia) were reviewed. These included all consecutive episodes seen in this population during an eight-month period, after excluding 10 patients in whom bronchoscopy was not performed. Of the 121 patients, seven were excluded because of inadequate follow-up. Of the remaining 114 patients, six had had two episodes of pneumonia during the study period. Since the first of the two episodes was known not to have caused death, it was excluded. In total, 114 episodes in 114 patients were studied.

Diagnostic criteria: For the purpose of the study, a diagnosis of CMV pneumonitis required all three of the following: a clinical picture of diffuse interstitial pneumonitis; the exclusion of other pathogens, Kaposi's sarcoma, and lymphoma by bronchoscopy, bronchial washings and brushings and appropriate cultures; and either a cytology with numerous viral inclusions or tissue (open lung biopsy) diagnosis of CMV pneumonitis. When those criteria were not met but the culture was positive for CMV, the patient was considered to have a respiratory $\mathrm{CMV}$ infection.

PCP was diagnosed when the characteristic cysts were identified in bronchoalveolar fluid by toluidine blue and methenamine silver stains. A diagnosis of (primary) bacterial infection required the exclusion of $P$ carinii, fungi and mycobacteria; the presence of a predominantly purulent sputum; peripheral neutrophilia; and the isolation of a known pulmonary pathogenic bacterium from cultures of sputum and/or blood. The diagnosis of nonspecific pneumonitis required the exclusion of any microorganism and clinical resolution without specific therapy.

Kaposi's sarcoma of the respiratory tract was diagnosed 
when typical endobronchial lesions were seen at the time of bronchoscopy or when it was documented by tissue diagnosis. Coexistence with pathogens was documented in some cases of respiratory Kaposi's sarcoma.

Clinical and laboratory information: Clinical information included demographic variables, symptoms at presentation and findings in the physical examination (including cutaneous Kaposi's sarcoma). It also included recent or current use of zidovudine treatment, time since diagnosis of HIV infection, previous episodes of PCP, need for hospital admission and days on supplemental oxygen.

All patients underwent bronchoscopy with bronchial washings and brushings within $48 \mathrm{~h}$ of their physician's evaluation. Informed consent was obtained for all procedures.

Bronchoscopy was performed using a fibreoptic bronchoscope under topical anesthesia with a lidocaine solution. The tip of the bronchoscope was placed in a subsegmental bronchus, usually in the lower lobes, and bronchial washing was performed as previously described (23). Bronchial brushings were also obtained in all cases.

The samples were sent to the laboratory within 15 to 30 mins after collection. Slides were prepared from bronchial brushings and cellular sediment from samples of the fluid. Cells were stained with toluidine blue and Papanicolaou stain, and examined under the microscope by two experienced laboratory technicians. Aliquots from bronchoalveolar fluid were made under sterile conditions and used for fungal, bacterial and mycobacterial cultures. For detection of CMV, centrifugation cultures were done (in duplicate) as per published protocols (24). Indirect immunofluorescence was used to visualize CMV antigens. A positive culture was determined by the presence of fluorescing nuclei in either one or both of the two vials.

Laboratory data also included chest radiograph, oxygen saturation (by pulse oxymetry) at the time of the bronchoscopy, as well as bacterial and fungal cultures of the bronchial washings and brushings. Additionally, serum lactate dehydrogenase (LDH), gallium scan of the lungs, $\mathrm{PaO}_{2}$ and alveolar-arterial oxygen gradient were available in a significant number of patients.

Follow-up and outcome measures: Follow-up was recorded for a minimum of four weeks after either the end of out-patient treatment or hospital discharge, and completed in all 114 episodes reported here.

Mortality was classified as occurring less or more than four weeks after discharge (for in-patients) or end of treatment (for out-patients). Short term mortality, that is, death before the time limit defined above, was considered to be directly related to the acute respiratory event. This time limit was chosen before both the data gathering and analysis took place.

Patients diagnosed as having PCP were subdivided according to the result of the culture for CMV. Clinical severity and short term mortality were compared between the two resulting groups (PCP with positive CMV culture, and $\mathrm{PCP}$ with negative CMV culture) in terms of all available clinical and laboratory data mentioned above, as well as other variables such as need
TABLE 1

Clinical characteristics of $114 \mathrm{HIV}$-infected patients at the time of their initial evaluation for pneumonia

\begin{tabular}{|c|c|}
\hline Age (years) ${ }^{*}$ & $38.1(37,25-71)$ \\
\hline Current zidovudine treatment & 47 \\
\hline \multicolumn{2}{|l|}{ Symptoms } \\
\hline Cough & $107(93.9 \%)$ \\
\hline Dyspnea & $101(88.6 \%)$ \\
\hline Fever & $79(69.3 \%)$ \\
\hline Duration (days) ${ }^{\dagger}$ & $20.6 \pm 28.3(14,1-224)$ \\
\hline \multicolumn{2}{|l|}{ CDC group classification } \\
\hline $0-1$ & 15 \\
\hline II-III & 24 \\
\hline IVC2 & 19 \\
\hline IV (except C2) & 56 \\
\hline \multicolumn{2}{|l|}{ Previous episodes of PCP } \\
\hline 0 & 84 \\
\hline 1 & 17 \\
\hline $2-5$ & 13 \\
\hline Pneumothorax & 6 \\
\hline Oxygen saturation $^{\dagger}$ & $0.91 \pm 0.07(0.93,0.52-0.98)$ \\
\hline $\mathrm{PaO}_{2}(\mathrm{kPa})$ & $8.9 \pm 1.9$ \\
\hline$(\mathrm{A}-\mathrm{a})$ oxygen gradient $(\mathrm{kPa})$ & $6.1 \pm 2.0$ \\
\hline Serum LDH (IU, normal <350) & $1293 \pm 885(991,389-5694)$ \\
\hline
\end{tabular}

${ }^{*}$ Mean (median, range); ${ }^{\dagger}$ Mean \pm standard deviation (median, range); A-a Alveolar-arterial; $C D C$ Centers for Disease Control and Prevention; HIV Human immunodeficiency virus; LDH Lactate dehydrogenase; PCP Pneumocystis carinii pneumonia

for hospital admission, current or recent (within three weeks of bronchoscopy) zidovudine treatment, duration of hospital stay, days on supplemental oxygen and use of steroids.

In this patient population, steroids were used most frequently $72 \mathrm{~h}$ or longer after admission, upon worsening of the clinical picture.

Data analysis: Statistical analysis was done with a SAS statistical package, release 6.03 (SAS Institute Inc, North Carolina). Median and ranges are presented when the data were not normally distributed. Two-tailed statistical significance testing was used throughout. The outcome was evaluated by means of the relative risk, with $95 \%$ CI. In order to analyze the data according to disease severity, those patients with CDC groups 0, I, II, III, and IVC2 (21) were considered to have 'earlier' HIV-related disease, and those in all other categories of CDC group IV were considered to have 'advanced' disease. Subgroup analysis was done using the conditional maximum likelihood estimate of the odds ratio (with exact $95 \% \mathrm{CI}$ ) as an approximation of the relative risk (25), using the StatXact statistical package (CYTEL Software Corporation, Massachusetts). $\chi^{2}$ tests were used in the comparisons that involved categorical variables and the Fisher's exact test, when any cell count in a $2 \times 2$ table was less than five. For continuous variables, unpaired $t$ tests were used to compare means when the data were normally distributed and the Wilcoxon rank sum test when they were not.

\section{RESULTS}

One hundred and fourteen episodes of pneumonia in 114 patients were analyzed. All the subjects were homosexual men, and most (110 of 114) were Causasian. Table 1 shows 
TABLE 2

Final diagnoses and clinical course of 114 HIV patients evaluated for pneumonia

\begin{tabular}{lc}
\hline Pneumocystis carinii pneumonia & 86 \\
With CMV & 1 \\
With Mycobacterium avium & 8 \\
With Mycobacterium tuberculosis & 1 \\
With pulmonary lymphoma & 1 \\
With respiratory Kaposi's sarcoma & 3 \\
$\quad$ With bacterial infection & 6 \\
CMV pneumonitis & 1 \\
Respiratory Kaposi's sarcoma & 3 \\
M avium pneumonia & 2 \\
Cryptococcosis & 1 \\
Tuberculosis & 1 \\
Nonspecific pneumonitis & 14 \\
Bacterial infections & 5 \\
Pulmonary lymphoma & 1 \\
Hospital stay (days) & \\
Treatment with steroids & $30.4 \pm 0.4(8,0-48)$ \\
Admitted to the hospital & 30 \\
Supplemental oxygen (days) & 87 \\
Mortality & $4.4 \pm 7.5(0,0-48)$ \\
$\quad$ Respiratory failure, less than four weeks & 13 \\
$\quad$ Nonrespiratory, four weeks & 1 \\
After four weeks & 5 \\
\hline
\end{tabular}

*Mean \pm standard deviation (median, range); CMV Cytomegalovirus

the clinical features and Table 2 the diagnoses and clinical course of these pneumonia cases. Admission to hospital was required in $87(76 \%)$ of the episodes of pneumonia, and steroids were used in 30 (26\%) cases. CMV cultures were positive in 57 (50\%) of the episodes. Patients with previouly diagnosed cutaneous Kaposi's sarcoma were more likely to have a positive CMV culture (13 of 57 versus four of 57, $\mathrm{P}=0.02)$. As expected, $P$ carinii was the leading cause of pneumonia, found in 86 cases $(72.5 \%$ of the studied episodes). Only two cases met the study criteria for CMV pneumonitis, one of which was in association with PCP.

Of the 86 patients with PCP, 45 were co-infected with CMV. Table 3 shows a comparison of some of the clinical data between PCP patients who were co-infected with CMV and those who were not. The two groups were comparable, and there was no difference in the number of patients who had received zidovudine treatment (recent or current) or PCP prophylaxis (with oral or inhaled regimens). Except for room air oxygen saturation at the time of bronchoscopy $(\mathrm{P}=0.04)$, no significant differences were found in any of the indicators of clinical severity of the pulmonary inflammation. Short term deaths occurred in eight of 45 PCP patients positive for CMV (seven of eight were due to respiratory failure), and in two of the 41 PCP patients negative for CMV (both from respiratory failure). The relative risk of short term mortality between the two groups of PCP patients was 3.64 (95\% CI 0.82 to 16.18 ).

Subgroup analysis based on CDC group classification (Table 4) revealed that the excess short term mortality was limited to the subgroup with earlier forms of HIV-related disease, as opposed to that with full-blown AIDS. In the
Table 3

Comparison of $\mathrm{PCP}+\mathrm{CMV}+$ versus $\mathrm{PCP}+\mathrm{CMV}-$ in HIV patients

\begin{tabular}{lccc}
\hline & PCP+CMV+ & PCP+CMV- $\mathbf{P}^{\dagger}$ \\
\hline Number & 45 & 41 & \\
Age (years) & 38.7 & 39.4 & NS \\
Symptom duration (days) & 25.9 & 18 & NS \\
Recent/current zidovudine & 18 & 17 & NS \\
CDC groups & & & \\
$\quad$ 0-I & 8 & 5 & NS \\
$\quad$ II-III & 7 & 12 & NS \\
$\quad$ IVC2 & 7 & 7 & NS \\
$\quad$ IV (except C2) & 23 & 17 & NS \\
Previous PCP & 12 & 9 & \\
Oxygen saturation* & 0.88 & 0.92 & 0.04 \\
PaO2 (kPa) & 8.6 & 9.0 & NS \\
(A-a) oxygen gradient (kPa) $^{*}$ & 6.6 & 6.1 & NS \\
Serum LDH (IU) & 1413.9 & 1430.5 & NS \\
Days on oxygen & 6.1 & 4.3 & NS \\
Steroids used & 17 & 12 & NS \\
Hospital stay (days) & 11.1 & 11.5 & NS \\
\hline
\end{tabular}

${ }^{*}$ Mean; ${ }^{\dagger}$ Wilcoxon rank sum test or $\mathrm{t}$ test, depending on whether the data are normally distributed; A-a Alveolar-arterial; CDC Centers for Disease Control and Prevention; CMV Cytomegalovirus; HIV Human immunodeficiency virus; LDH Lactate dehydrogenase; NS Not significant; $P C P$ Pneumocystis carinii pneumonia; $P C P+C M V+P C P$ with positive $C M V$ culture of bronchoalveolar fluid; $P C P+C M V-P C P$ with negative CMV culture of bronchoalveolar fluid

former subgroup, the odds ratio for short term mortality was infinity for both respiratory and all-cause deaths, with a lower 95\% exact CI limit of 1.5 . In the subgroup with advanced HIV disease, on the other hand, the odds ratios for short term mortality was 1.12 (95\% exact CI 0.11 to 15.02 ).

Irrespective of their CMV co-infection status, for nine of the 10 patients with PCP who died, the episode under study was their first. Most had not been (currently or recently) on zidovudine (eight of 10), and practically all of them had steroids added to their treatment (nine of 10) as respiratory insufficiency worsened.

The remaining 28 patients who did not have $\mathrm{PCP}$ were, as expected, clinically less severely compromised (eg, significantly lower serum LDH and higher oxygen saturation; data not shown). Respiratory CMV infection correlated with the presence of cutaneous $(\mathrm{P}=0.005)$ and respiratory $(\mathrm{P}=0.040)$ Kaposi's sarcoma, but was not associated with short term mortality.

\section{DISCUSSION}

In agreement with previous studies (14), the results of our study demonstrate that CMV infection of the respiratory tract is very common in HIV patients, more so in those with previously diagnosed cutaneous Kaposi's sarcoma $(26,27)$. CMV pneumonitis, on the other hand, seems to be infrequent. In our study population (essentially all HIV-infected homosexual men), the results also suggest that a positive CMV culture from fluid may be associated with an increased short term mortality from PCP. The increased risk of death from CMV co-infection in patients with PCP seemed to be limited to those individuals in CDC classes 0 to III and IVC2, as 
opposed to those in other group IV categories. We did not detect any evidence of increased clinical severity by any of the standard indicators used, on presentation and/or before the bronchoscopic procedure, except for oxygen saturation.

In assessing whether the finding of a CMV-positive bronchoalveolar fluid culture was associated with a worse prognosis of PCP, we considered severity on presentation and short term mortality more appropriate than long term mortality. The latter is very likely to reflect the combined effects of multiple infectious and noninfectious complications characteristic of AIDS, and survival analysis of our cohort (Kaplan-Meier method; data not presented) confirmed this assumption. That an increased short term mortality in patients with CMV respiratory co-infection is suggested, but an increased clinical severity was not detected, may be explained by the fact that clinical severity was only assessed on presentation and before bronchoscopy, and that the only clinical end-point assessed after bronchoscopy was mortality.

Although the CDC classification was not intended to be a staging system, it is reasonable to assume less compromise in patients with stages 0 to III and IVC2 (oral candidiasis in our patients), than in those in other group IV categories. Any misclassification would have been expected to be random, and thus to decrease the measure of the association (ie, favouring the null hypothesis).

Our results on the association of respiratory CMV infection with prognosis of PCP generally agree with those of Stover et al (5), although that group reported a seemingly stronger effect of CMV co-infection on PCP mortality. There are some differences between their study and ours which may account for this. Our sample of cases with PCP was considerably larger (86 versus 35), as was the proportion of patients co-infected with CMV (50\% versus 37\%). Mortality, however, was much higher in their group of patients (43\% versus $11.6 \%$ ) and their number of cases of CMV pneumonitis (eight) was larger than ours (two). One possible explanation for this last discrepancy is that their definition of CMV pneumonitis was clearly less stringent than ours; that study equated positivity of CMV culture in bronchoalveolar fluid with CMV pneumonitis, in at least some of their cases. Additional probable differences are the greater heterogeneity of their study group (eg, risk factors for HIV disease) and the patient referral basis of the two studies. Of any group in society, homosexual men have had the highest prevalence of CMV seropositivity, and this may need to be taken into account in future studies of the natural history of CMV infection in HIV patients.

Our study also differs from others $(10,11,16)$ that have not corroborated Stover's findings, and several design issues may have accounted for this. The prevalence of CMV infection in the sample populations in two of those studies (19\% and $36 \%)(10,16)$ was lower than in ours, and the resulting comparison groups were fairly uneven with very small groups of PCP with positive CMV culture of bronchoalveolar fluid. Mortality was lower than in our series in two of those studies $(10,11)$, and this is very likely to have prevented the detection of a difference in outcome. Besides, sample size
TABLE 4

\begin{tabular}{|c|c|c|c|c|}
\hline & & & CDC TV & xcept C2) \\
\hline & $\begin{array}{l}\mathrm{PCP}+ \\
\mathrm{CMV+}\end{array}$ & $\begin{array}{l}\mathrm{PCP}+ \\
\mathrm{CMV}-\end{array}$ & $\begin{array}{l}\mathrm{PCP}+ \\
\mathrm{CMV}+\end{array}$ & $\begin{array}{l}\mathrm{PCP}+ \\
\mathrm{CMV}-\end{array}$ \\
\hline & 22 & 24 & 23 & 17 \\
\hline Deaths & 5 & 0 & 3 & 2 \\
\hline OR $(95 \% \mathrm{Cl})$ & & $0-\infty)$ & 1.12( & 1-15.02) \\
\hline
\end{tabular}

CDC Centers for Disease Control and Prevention; Cl Confidence interval; CMV Cytomegalovirus; PCP Pneumocystis carinii pneumonia; $P C P+C M V+P C P$ with positive $C M V$ culture of bronchoalveolar fluid; $P C P+C M V-P C P$ with negative $C M V$ culture of bronchoalveolar fluid; OR Odds ratio

was smaller in the study by Miles et al (11) and, in a recent reanalysis of their past experience, these investigators seem to be revising their conclusions (28).

The limitations of the current noninvasive diagnostic methods (culture techniques and cytology of fluid samples) may also contribute to the rarity of CMV pneumonitis diagnoses. A noninvasive quantitative test is needed that can reliably point to an uninhibited viral replicative cycle, with high copy numbers of virus, which very likely characterizes severe CMV pneumonia for which treatment could be indicated.

The spectrum of clinical presentation of CMV respiratory infections in HIV-infected patients appears to be broader than what is usually expected from this pathogen. In the setting of HIV infection, and for reasons that are not clear, CMV often causes a subclinical chronic respiratory infection and only occasionally severe pneumonitis. It has been hypothesized that CMV pneumonitis requires an active immune response $(10,29)$. If this proves to be true, it could help explain the higher mortality in PCP and CMV co-infected patients with earlier HIV disease observed in our study.

Although ours and other clinical studies suggest that CMV frequently has a pattern of chronic infection in the respiratory tract of HIV patients, autopsy studies (7-9) have documented CMV pneumonitis in $60 \%$ of AIDS patients. It is usually considered that active CMV pneumonitis more frequently represents a reactivation of a latent disease rather than a primary infection (30). In the case of HIV-infected homosexual men, a reactivation of the CMV infection may occur as a preterminal event in the course of PCP and this may indeed contribute to the death of a significant number of patients. That preterminal reactivation would explain the failure to detect any evidence of more severe compromise in co-infected patients at the time of the initial clinical evaluation. Furthermore, this respiratory co-infection with CMV and $P$ carinii may affect short term mortality from pneumonia only in a subset of patients who at present we can only characterize as those with earlier stages of the disease. The importance of recognizing this fact relates to the potential to decrease further mortality from pneumonia in AIDS with treatment for CMV in some patients. If that goal is to be realized, closer clinical and pathological correlation and improved diagnostic techniques (rapid, noninvasive and quanti- 
tative) are needed to clarify the role that CMV plays in the respiratory morbidity and mortality of HIV-infected patients.

ACKNOWLEDGEMENTS: This work was submitted as partial fulfillment of the requirement for the MPH degree of the first author at Yale University School of Medicine. The authors acknowledge the support and helpful suggestions of Drs Raúl Sansores, Mark R Cullen and George Friedman-Jiménez, as well as institutional support from Yale University and New York University schools of medicine.

\section{REFERENCES}

1. Murray JF, Felton CP, Garay SM, Gottlieb MS, Hopewell PC, Stover DE. Pulmonary complications of the acquired immunodeficiency syndrome - Report of a National Heart, Lung, and Blood Institute workshop. N Engl J Med 1984;310:1682-8.

2. Pass HI, Potter DA, Macher AM, Reichert D, Shelhammer JH, Masur H. Thoracic manifestations of the acquired immune deficiency syndrome. J Thorac Cardiovasc Surg 1984;88:654-8.

3. Wallace JM. Pulmonary infection in human immunodeficiency disease: Viral pulmonary infections. Semin Respir Med 1989;4:147-54.

4. Schooley RT. Cytomegalovirus in the setting of infection with human immunodeficiency virus. Rev Infect Dis 1990;12(Suppl 7):S811-9.

5. Stover DE, White DA, Romano PA, Gellene RA, Robeson WA. Spectrum of pulmonary diseases associated with the acquired immunodeficiency syndrome. Am J Med 1985;78:429-37.

6. Drew WL. Cytomegalovirus infection in patients with AIDS. J Infect Dis 1988;158:449-56.

7. Wallace JM, Hannah J. Cytomegalovirus pneumonitis in patients with AIDS - Findings in an autopsy series. Chest 1987;92:198-203.

8. Nash G, Fligiel S. Pathologic features of the lung in the acquired immune deficiency syndrome (AIDS): An autopsy study of seventeen homosexual males. Am J Clin Pathol 1984;81:6-12.

9. Hui AN, Koss MN, Meyer PR. Necropsy findings in acquired immunodeficiency syndrome: A comparison of premortem diagnoses with postmortem findings. Hum Pathol 1984;15:670-6.

10. Millar AB, Patou G, Miller RF, et al. Cytomegalovirus in the lungs of patients with AIDS: Respiratory pathogen or passenger? Am Rev Respir Dis 1990;141:1474-7.

11. Miles PR, Baughman RP, Linnemann CC. Cytomegalovirus in the bronchoalveolar lavage fluid of patients with AIDS. Chest 1990;97:1072-6.

12. Jacobson MA, Mills J, Rush J, et al. Morbidity and mortality of patients with AIDS and first-episode Pneumocystis carinii pneumonia unaffected by concomitant pulmonary cytomegalovirus infection. Am Rev Respir Dis 1991;144:6-9.

13. Bozzette SA, Arcia J, Bartok AE, et al. Impact of Pneumocystis carinii and cytomegalovirus on the course and outcome of atypical pneumonia in advanced human immodeficiency virus disease. J Infect Dis 1992;165:93-8.

14. Broaddus C, Dake MD, Stulbarg MS, Blumenfeld W, Hadley K, Golden JA. Bronchoalveolar lavage and transbronchial biopsy for the diagnosis of pulmonary infections in the acquired immunodeficiency syndrome. Ann Intern Med 1985;102:747-52.

15. Jacobson MA, Mills J. Cytomegalovirus infection. Clin Chest Med 1988;9:442-8.

16. Bower M, Barton SE, Nelson MR, et al. The significance of the detection of cytomegalovirus in the bronchoalveolar lavage fluid in AIDS patients with pneumonia. AIDS 1990;4:317-20.

17. Harzic M, Hazeron MC, Bertrand C. Évaluation de la détection des anticorps sériques anti-CMV appliquée au diagnostic de l'infection récente. Ann Med Interne 1987;138:331-3.

18. Panjwani DD, Ball MG, Berry NJ, Wimperis JZ, Blacklock HA, Prentice HG. Virological and serological diagnosis of cytomegalovirus infection in bone marrow allograft recipients. J Med Virol 1985;16:357-65.

19. Paradis IL, Grgurich WF, Dummer JS, Dekker A, Dauber JH. Rapid detection of cytomegalovirus pneumonia from lung lavage cells. Am Rev Respir Dis 1988;138:697-702.

20. Zurlo JJ, O’Neill D, Polis MA, et al. Lack of clinical utility of cytomegalovirus blood and urine cultures in patients with HIV infection. Ann Intern Med 1993;118:12-7.

21. Centers for Disease Control. Classification system for human T-lymphotropic virus type III/lymphadenopathy-associated virus infections. Ann Intern Med 1986;105:234-7.

22. Kramer EL, Sanger JJ, Garay SM, et al. Gallium-67 scans of the chest in patients with the acquired immunodeficiency syndrome. J Nucl Med 1987;28:1107-14.

23. Lam S, Leriche JC, Kijek K, Phillips D. Effect of bronchial lavage volume on cellular and protein recovery. Chest 1985;88:856-9.

24. Smith TF, Espy MJ. Rapid viral diagnosis using the shell vial technique. Pan Am Group Rapid Viral Diagnosis 1987;13:1-3.

25. Santner TJ, Snell MK. Small-sample confidence intervals for $p_{1}-p_{2}$ and $p_{1} / p_{2}$ in $2 \times 2$ contingency tables. J Am Stat Assoc 1980;75:386-94.

26. Giraldo G, Beth E. The involvement of cytomegalovirus in acquired immunodeficiency syndrome and Kaposi's sarcoma. Prog Allergy 1986;37:319-31.

27. Griffiths PD, Grundy JE. The status of CMV as a human pathogen. Epidemiol Infect 1988;100:1-15.

28. Hayner CE, Baughman RP, Dohn MN, Linnemann CC. The impact of positive cytomegalovirus cytology found by bronchoalveolar lavage on survival in patients with human immunodeficiency virus. Am Rev Respir Dis 1993;147:A407. (Abst)

29. Grundy JE, Shanley JD, Griffiths PD. Is cytomegalovirus interstitial pneumonitis in transplant recipients an immunopathological condition? Lancet 1987;ii:996-8.

30. Alford CA, Britt WJ. Cytomegalovirus. In: Fields BN, ed. Virology. New York: Raven Press, 1985:629-59. 


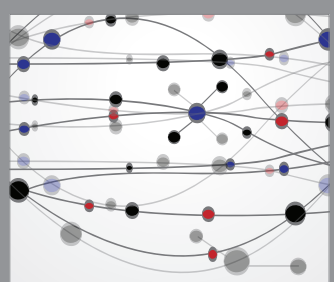

The Scientific World Journal
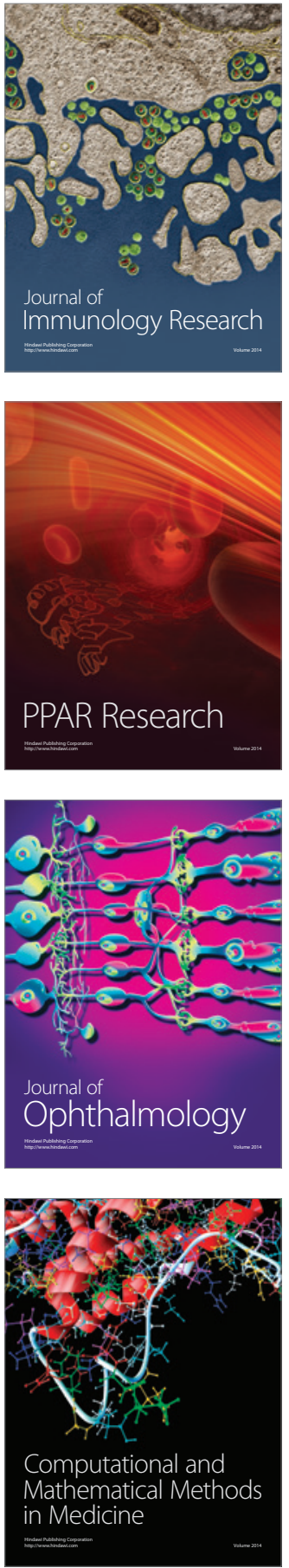

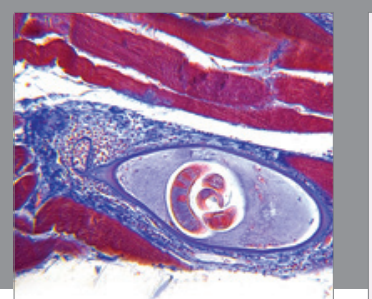

Gastroenterology Research and Practice

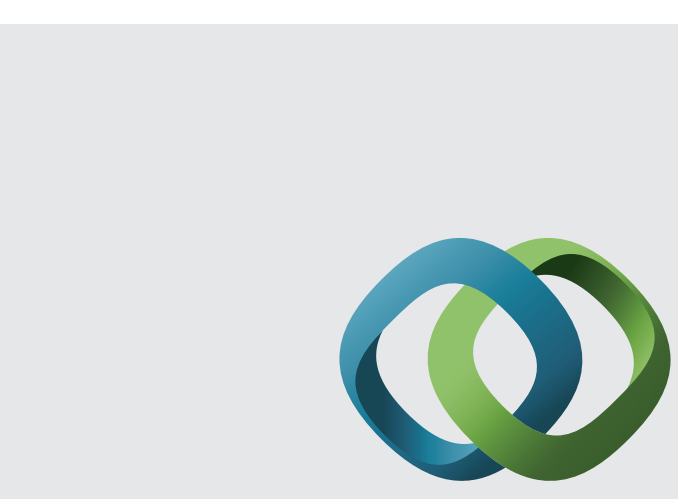

\section{Hindawi}

Submit your manuscripts at

http://www.hindawi.com
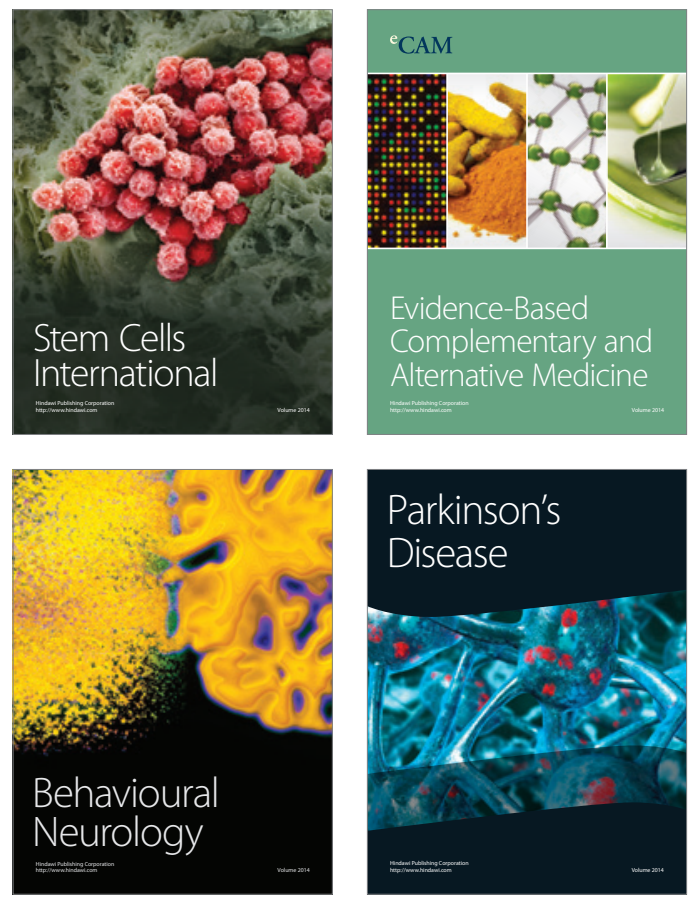
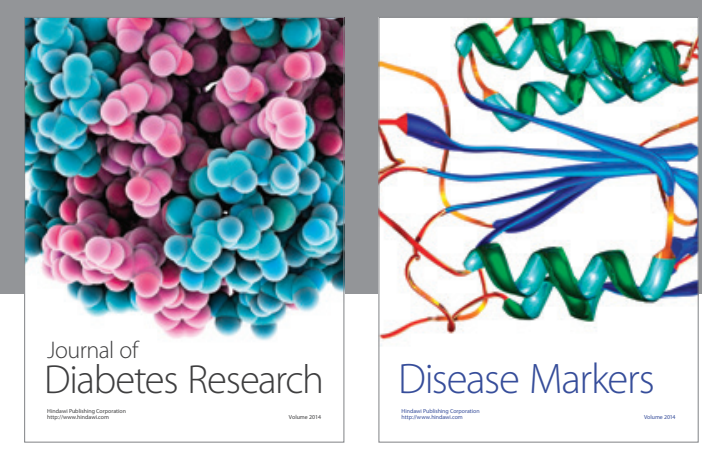

Disease Markers
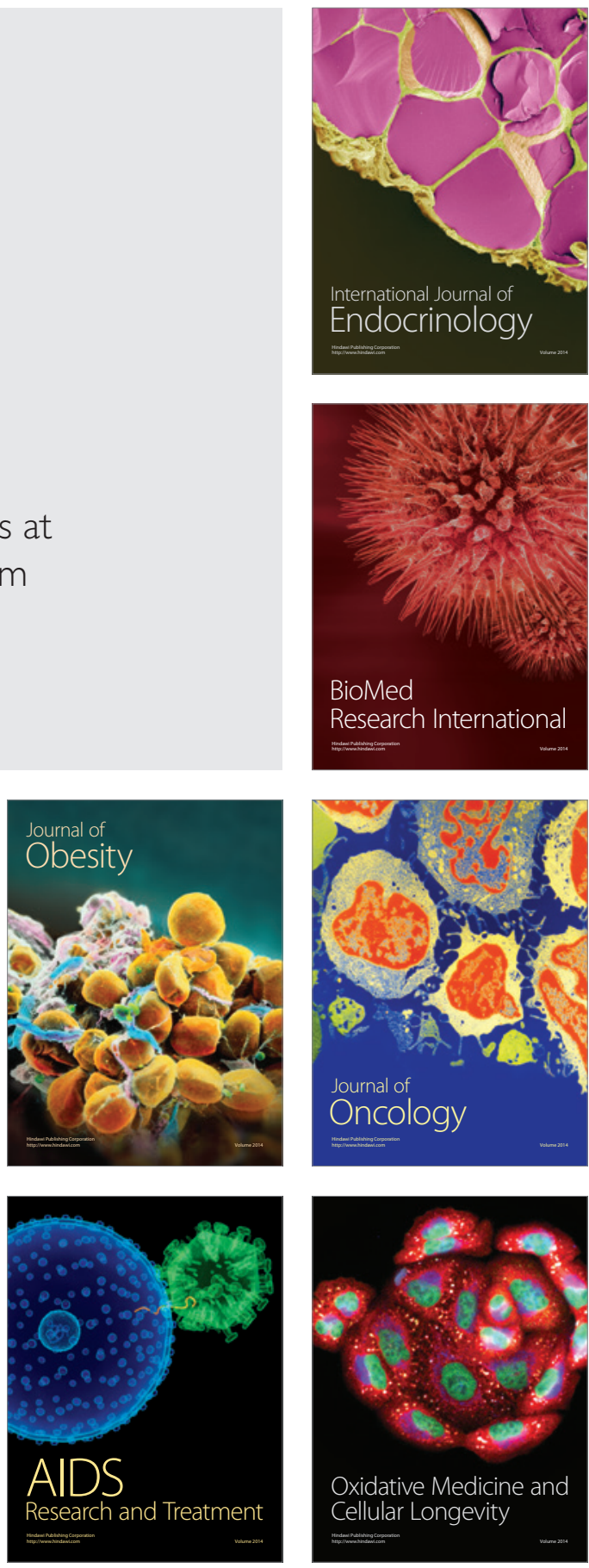